\title{
Prevalence of vitamin d deficiency among overweight and obese Libyan females
}

\begin{abstract}
Globally, overweight and obesity are the fifth leading contributors to fatalities According to the World Health Organization (WHO), overweight is defined as a body Mass Index $(B M I) \geq 25$, whereas obesity is a $B M I \geq 30$. There is growing evidence that obesity and vitamin D deficiency are related, although the cause-effect relationship remains unclear. Objective of this work was to find out whether obesity alters vitamin D level in obese adult females in the Eastern region of Libya. One hundred and twenty Libyan females visited nutrition clinics both in Benghazi and Tobruk were interviewed during September 2015 with the aid of a structured questionnaire. Tested individuals were subjected to thorough clinical investigations and biochemical measurement of vitamin D, calcium, lipid profile, fasting blood glucose, Hemoglobin A1c (HbA1c), Complete Blood Count (CBC), creatinine, $\mathrm{Na}+, \mathrm{K}+$, urea and Thyroid Stimulating Hormone (TSH) levels that were carried out on the collected serum. Data was analyzed using excel and presented as the mean \pm SEM (n). The mean age of study sample was $30.93 \pm 1.05$ y (118). Adult obese Libyan females represented $63.33 \%$, adult overweight Libyan females represented $25.83 \%$, adult healthy Libyan females represented $3.33 \%$ and children (Libyan females $<18$ years old) represented $7.50 \%$ of whole study sample. Out of whole study sample $55.83 \%(n=67)$ had a family history of obesity. Average level of vitamin D in overweight adult Libyan females was $9.92 \pm 1.37$ (29), obese adult Libyan females was $9.38 \pm 0.70$ (74), healthy weight adult Libyan females was $11.11 \pm 1.72$ (4) and in female Libyan children was 9.98 \pm 1.63 (9). Vitamin D deficiency is highly prevalent not only in overweight and obese Libyan adult females but also this may be extended to children and healthy adults as well. This study should be extended to measure vitamin D level among different ages and sexes in all main cities within the country.
\end{abstract}

Keywords: obesity, vitamin D, overweight, Benghazi, Libya
Volume 6 Issue 6 - 2018

\author{
Fatima Mohammed Helal,' Amira Faraj,' \\ Narges Kablan, ${ }^{2}$ Mustafa Elfakhri, ${ }^{3}$ Salma \\ Bukhatwa ${ }^{2}$ \\ 'Department of Pharmacology, Faculty of Pharmacy, Libyan \\ International Medical University, Libya \\ ${ }^{2}$ Department of Pharmacology \& Toxicology, Faculty of \\ Pharmacy, University of Benghazi, Libya \\ ${ }^{3}$ Department of Biochemistry, Faculty of Medicine, University of \\ Benghazi, Libya
}

\begin{abstract}
Correspondence: Salma A Bukhatwa, Department of Pharmacology \& Toxicology, Faculty of Pharmacy, University of Benghazi, Benghazi, Libya, Tel 00218917240179 , Fax 002186I223 I520, Email salma.bukhetwa@uob.edu.ly, sbukhetwa@icloud.com
\end{abstract}

Received: May 01, 2017 | Published: November 27, 2018
Abbreviations: WHO; world health organization, BMI; body mass index, $\mathrm{CBC}$; complete blood count, $\mathrm{HbA1c}$; hemoglobin $\mathrm{A} 1 \mathrm{c}$, $\mathrm{TSH}$; thyroid stimulating hormone

\section{Introduction}

Obesity is a medical condition in which excess body fat has accumulated to the extent that it may have a negative effect on health, leading to reduced life expectancy and/or increased health problems. According to the World Health Organization (WHO), Body Mass Index (BMI) greater than or equal to 25 is overweight and a BMI greater than or equal to 30 is obesity. ${ }^{2}$ Obesity and overweight result in major morbidity and premature death as they are predisposing factors for diabetes mellitus, hypertension, dyslipidemia, osteoarthritis, certain malignancies, and others. ${ }^{3-5}$ The risk of chronic disease in populations increases progressively from a BMI of $21 \mathrm{~kg} / \mathrm{m}^{2}{ }^{6}$ In Libya, some studies showed that obesity is more prevalent among people with type 2 diabetics, ${ }^{7}$ hypertension, ${ }^{8}$ females with polycystic ovary disease, ${ }^{9}$ and patients with benign intracranial hypertension than among the general population, which indirectly indicates that these diseases are more prevalent among obese than non-obese Libyans. ${ }^{6}$ Obesity is highly prevalent in Libyan adults, ${ }^{10}$ which raises the possibility of environmental factors as the main cause of the increased prevalence of adult obesity in Libya. ${ }^{6}$

Vitamin D deficiency is now recognized as a pandemic particularly in the northern hemisphere where winters are severe and sun exposure is minimal. The biomarker of vitamin D status is the level of circulating calcidiol $[25(\mathrm{OH}) \mathrm{D}]$, which due to its lipophilic nature distributes into the adipose tissue and represents the storage form of vitamin D with a half-life of 15 days. Vitamin D deficiency is defined as a calcidiol level $<20 \mathrm{ng} / \mathrm{mL}$, insufficiency as a level of $21-29 \mathrm{ng} /$ $\mathrm{mL}$, and sufficiency as a level $>30 \mathrm{ng} / \mathrm{mL}(1 \mathrm{ng} / \mathrm{mL}=2.5 \mathrm{nmol} / \mathrm{L})$. In current medical practice, these reference ranges are gradually shifting upward as vitamin D deficiency is increasingly being implicated in the etiology of an expanding list of diseases. ${ }^{11-13}$ The reasons for vitamin deficiency are multiple and include indoor life style, high latitude, dark skin, insufficient skin area exposed to UVB, obesity (expanded volume of distribution), aging (reduced capacity for photosynthesis), severe liver disease, and chronic kidney disease..$^{14,15}$

Vitamin D deficiency has been linked with significant complications such as cardiovascular events, obesity, metabolic syndrome, type 2 diabetes, various types of cancer, immune disorders, increased mortality and adverse pregnancy outcomes. ${ }^{16-18}$ However, in most of these conditions a causal relationship and the pathophysiological mechanisms involved have not yet been established. The link between obesity and vitamin D deficiency has been observed for years but determining the cause and effect has been difficult. Nonetheless, experimental studies have demonstrated that $1,25(\mathrm{OH})_{2} \mathrm{D}_{3}$ plays an active role in adipose tissue by modulating inflammation, adipogenesis and adipocyte secretion as the key component of metabolic disorders e.g. in the metabolic syndrome. ${ }^{19}$ Main objective of this work was to find out whether obesity alters vitamin D level in obese adult females in the Eastern region of Libya. 


\section{Material and methods}

Study protocol was approved by Ethical Committee at Libyan International Medical University. All study subjects showed their agreement to participate in the study by signing a consent. Data was collected during the period $7^{\text {th }}-16^{\text {th }}$ September, 2015 from 120 Libyan females visited nutrition clinics both in Benghazi and Tobruk cities in the Eastern region of Libya. The investigators interviewed each subject and collected information with the aid of a structured questionnaire that included basic information regarding the study subjects as follow: Age, ethnicity, weight, height, waist size, body mass index, income monthly, education, smoking, family history, coexistent risk factors, hours of daily sport, hours sitting to the computer and drug treatment taking by patients. Clinical investigations tests carried out on the collected serum included: fasting blood glucose, $\mathrm{HbAlc}$, lipid profile, renal function, Complete Blood Count (CBC), vitamin D; 25(OH) vitamin D (calcidiol), calcium and Thyroid Stimulating Hormone (TSH). All data was presented as mean \pm SEM (n) or percentage (\%) as required. Excel was used for statistical analysis of data.

\section{Results}

\section{Baseline criteria of study subjects}

Mean age (years) \pm SEM of study sample was $30.93 \pm 1.05$ ( $\mathrm{n}=118)$ with 2 subjects' weight were excluded (Table 1). Libyan females with white ethnicity represented $95 \%(n=114)$ of study sample, meanwhile Libyan females with black ethnicity represented $5 \%(n=6)$ of study sample (Table 1). Mean weight $(\mathrm{kg}) \pm$ SEM of study sample was $86.79 \pm 1.47(\mathrm{n}=120)$, mean height $(\mathrm{cm}) \pm$ SEM of study sample was $161.94 \pm 0.65(\mathrm{n}=120)$, mean waist size $(\mathrm{cm}) \pm$ SEM of study sample was $99.38 \pm 2.93(n=32)$ (Table 1). Illiterate Libyan females represented $6.67 \%(\mathrm{n}=8)$ of study sample, primary school attendants represented $28.33 \%(n=34)$ and higher education attendants represented $65 \%$ $(\mathrm{n}=78)$ (Table.1). All study subjects were non-smokers (Table 1). Monthly income of $8.33 \%(\mathrm{n}=10)$ of study sample was $<500 \mathrm{LD}$, monthly income of $35.00 \%(n=42)$ of study sample was $500 \mathrm{LD}$, monthly income of $18.33 \%(n=22)$ of study sample was 1000 LD, monthly income of $3.33 \%(n=4)$ of study sample was $1500 \mathrm{LD}$, monthly income of $2.50 \%(n=3)$ of study sample $>1500$ LD, noting that $32.5 \%(n=39)$ of study sample has no income (Table 1). Out of whole study sample $55.83 \%(\mathrm{n}=67)$ had a family history of obesity and in about $80 \%$ of them this family history was from either mother side alone or father side alone or from both mother and father (Table 1). Out of whole study sample adult $60 \%$ used to exercise at once a week for 30-6 min (Table1). Also, out of whole study subjects about $60 \%$ used to sit to computer at least $1 \mathrm{hrs} /$ day (Table 1).

\section{Body mass index distribution over study sample}

Obese adult Libyan females represented $63.33 \%$ of study sample, overweight adult Libyan females represented $25.83 \%$ of study sample, healthy adult Libyan females represented $3.33 \%$ of study sample and female Libyan children ( $<18$ years old) represented $7.50 \%$ of study sample (Figure 1).

\section{Clinical investigations data}

Clinical investigations data collected included vitamin D, calcium, lipid profile (Cholesterol, Triglycerides, HDL, LDL, VLDL) fasting blood glucose, Hemoglobin A1c (HbA1c), Complete Blood Count $(\mathrm{CBC})$, creatinine, $\mathrm{Na}^{+}, \mathrm{K}^{+}$, urea and $\mathrm{TSH}$ levels measurement. Mean vitamin D level in obese and overweight adult Libyan females was $9.91 \pm 0.63$ (103), in healthy weight adult Libyan females was
$11.11 \pm 1.72$ (4) and in female Libyan children was $9.98 \pm 1.63$ (9) (Table 2). Mean \pm SEM level of all other clinical investigations results are listed in (Table 2).

Table I Baseline criteria study subjects

\begin{tabular}{|c|c|c|c|}
\hline & Mean \pm SEM & $\mathbf{n}$ & $\%$ \\
\hline Age (Years) & $30.93 \pm 1.05$ & 118 & \\
\hline \multicolumn{4}{|l|}{ Ethnicity } \\
\hline White & & 114 & 95 \\
\hline Black & & 6 & 5 \\
\hline Weight (Kg) & $86.79 \pm 1.47$ & 120 & \\
\hline Height (cm) & $161.94 \pm 0.65$ & 120 & \\
\hline Waist size $(\mathrm{cm})$ & $99.38 \pm 2.93$ & 32 & \\
\hline \multicolumn{4}{|l|}{ Education } \\
\hline Illiterate & & 8 & 6.67 \\
\hline Primary school attendant & & 34 & 28.33 \\
\hline Higher education attendant & & 78 & 65 \\
\hline \multicolumn{4}{|l|}{ Monthly income (LD) } \\
\hline No income & & 39 & 32.5 \\
\hline$<500$ & & 10 & 8.33 \\
\hline 500 & & 42 & 35 \\
\hline 1000 & & 22 & 18.33 \\
\hline 1500 & & 4 & 3.33 \\
\hline$>1500$ & & 3 & 2.5 \\
\hline \multicolumn{4}{|l|}{ Smoking habbits } \\
\hline Smokers & & 0 & 0 \\
\hline Non-smokers & & 120 & 100 \\
\hline \multicolumn{4}{|l|}{ Family history of obesity } \\
\hline With family history & & 67 & 55.83 \\
\hline Father side & & 15 & 22.39 \\
\hline Mother side & & 25 & 37.31 \\
\hline Father \& mother side & & 14 & 20.9 \\
\hline Father, mother \& brothers & & 2 & 2.1 \\
\hline Mother \& brothers & & 5 & 7.5 \\
\hline Brother \& sister & & 6 & 8.1 \\
\hline With No family history & & 53 & 44.17 \\
\hline \multicolumn{4}{|c|}{ Daily sport activity (30-60min) } \\
\hline Yes & & 71 & 59.17 \\
\hline$>3 \mathrm{~d} /$ week & & 50 & 41.7 \\
\hline$<3 \mathrm{~d} /$ week & & 21 & 17.5 \\
\hline No & & 49 & 40.83 \\
\hline \multicolumn{4}{|l|}{ Hour/day sitting to computer } \\
\hline 0 & & 51 & 42.5 \\
\hline $1 \mathrm{hr}$ & & 21 & 17.5 \\
\hline $2 \mathrm{hr}$ & & 15 & 12.5 \\
\hline $5 \mathrm{hr}$ & & 25 & 20.83 \\
\hline $12 \mathrm{hr}$ & & 8 & 6.67 \\
\hline$>12$ & & 0 & 0 \\
\hline
\end{tabular}


Table 2 Clinical investigations data of study sample

\begin{tabular}{|c|c|c|c|c|}
\hline & $\begin{array}{l}\text { Mean } \pm \text { SEM(n) Obese and } \\
\text { Overweight adults }\end{array}$ & $\begin{array}{l}\text { Mean } \pm \operatorname{SEM}(n) \text { Healthy } \\
\text { weight adult }\end{array}$ & $\begin{array}{l}\operatorname{Mean} \pm \operatorname{SEM}(\mathbf{n}) \\
\text { Children }\end{array}$ & Reference value \\
\hline Vitamin D (ng/ml) Calcidiol & $9.91 \pm 0.63(103)$ & $11.11 \pm 1.72(4)$ & $9.98 \pm 1.63(9)$ & $30-80 \mathrm{ng} / \mathrm{ml}$ \\
\hline Calcium (mg/L) & $9 \pm 0.08(62)$ & $6.58 \pm 2.19(3)$ & $7.29 \pm 1.39(7)$ & $8.1-11.0 \mathrm{mg} / \mathrm{L}$ \\
\hline Cholesterol (mg/dl) & $176.96 \pm 4.56(98)$ & $169.75 \pm 15.67(4)$ & $118 \pm 24.08(7)$ & $50-200 \mathrm{mg} / \mathrm{dl}$ \\
\hline Triglycerides (mg/dl) & $120.65 \pm 6.06(96)$ & $93.75 \pm 17.96(4)$ & $93.78 \pm 22.48(7)$ & $50-200 \mathrm{mg} / \mathrm{dl}$ \\
\hline HDL (mg/dl) & $50.45 \pm 1.35(87)$ & $36.75 \pm 12.79(3)$ & $32.65 \pm 7.32(7)$ & $40-110 \mathrm{mg} / \mathrm{dl}$ \\
\hline $\mathrm{LDL}(\mathrm{mg} / \mathrm{dl})$ & $107.27 \pm 4.17(87)$ & $75 \pm 28.29(3)$ & $75.36 \pm 16.97(7)$ & $55-130 \mathrm{mg} / \mathrm{dl}$ \\
\hline VLDL (mg/dl) & $24.50 \pm 1.44(70)$ & $16.55 \pm 6.38(3)$ & $18.51 \pm 4.50(7)$ & $10-40 \mathrm{mg} / \mathrm{dl}$ \\
\hline Fasting blood glucose (mg/dl) & $97.27 \pm 3.19(82)$ & $65.25 \pm 22.48(3)$ & $80.33 \pm 15.54(7)$ & $70-115 \mathrm{mg} / \mathrm{dl}$ \\
\hline HbA1c( \%) & $0.06 \pm 0.0038(24)$ & - & - & $4.5-6 \%$ \\
\hline RBC (Millions/ul) & $4.54 \pm 0.05(100)$ & $4.12 \pm 0.07(4)$ & $3.69 \pm 0.703(7)$ & 3.80-5.80 Millions/ul \\
\hline WBC $\left(10^{3} / \mathrm{ul}\right)$ & $7.15 \pm 0.17(98)$ & $6.53 \pm 2.46(3)$ & $6.12 \pm 1.24(7)$ & 4-11 103/ul \\
\hline Creatinine (mg/dl) & $0.61 \pm 0.05(16)$ & - & & $0.5-1.3 \mathrm{mg} / \mathrm{dl}$ \\
\hline $\mathrm{NA}^{+}(\mathrm{mmol} / \mathrm{L})$ & $138.84 \pm 2.09(11)$ & - & $2-141$ & $135-145 \mathrm{mmol} / \mathrm{L}$ \\
\hline $\mathrm{K}^{+}(\mathrm{mmol} / \mathrm{L})$ & $4.20 \pm 0.13(9)$ & - & $2-4.1$ & $3.5-5.3 \mathrm{mmol} / \mathrm{L}$ \\
\hline Urea (mg/dl) & $24.56 \pm 2.42(16)$ & - & & $10-50 \mathrm{mg} / \mathrm{dl}$ \\
\hline TSH (ulU/ml) & $2.02 \pm 0.41(9)$ & - & 4- 5.635 & $0.27-4.2 \mathrm{ulU} / \mathrm{ml}$ \\
\hline
\end{tabular}

HDL; high-density lipoprotein, LDL; low-density lipoprotein,VLDL very-low-density lipoprotein, HbA Ic; glyco hemoglobin, RBC; red blood cell,WBC; white blood cell,TSH; thyroid stimulating hormone

$$
\begin{aligned}
& \text { Children } \\
& \text { Adult healthy }(18.5-24.9) \\
& \text { Adult over weight }(25-29.9) \\
& \text { Adult obese }(\geq 30)
\end{aligned}
$$

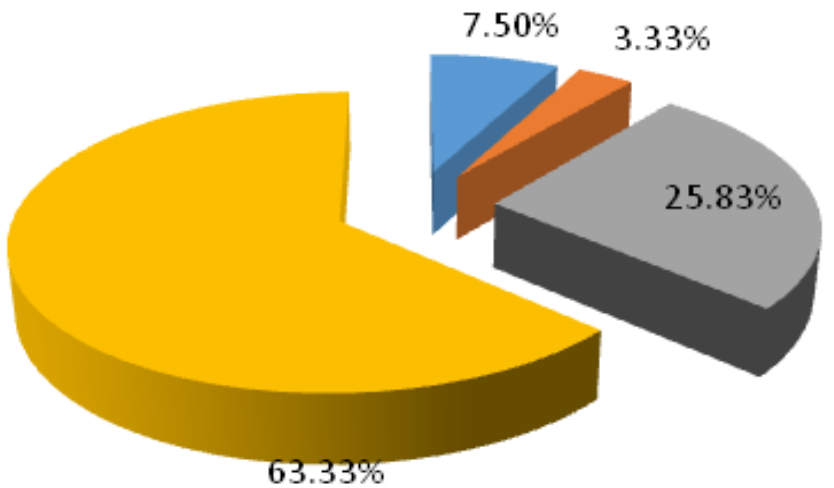

Figure I Body mass index distribution over study sample.

\section{Distribution of obese and non-obese subjects across the vitamin $D$ range}

Most of Libyan females experienced a deficiency in vitamin D with level $<20 \mathrm{ng} / \mathrm{ml}$. Much less subjects experienced insufficiency in vitamin D with level 21-29ng/ml. Very few subjects experienced a sufficient vitamin D level with concentration $>30 \mathrm{ng} / \mathrm{ml}$ (Figure 2).

\section{Discussion}

This study was conducted in the Eastern region of Libya during the period $7^{\text {th }}-16^{\text {th }}$ September, 2015 and included Libyan females who visited nutrition clinics, at the two largest cities in the Eastern region of Libya; Benghazi and Tobruk. More than $80 \%$ of study sample did not expose any of the common risk factors such as obesity even 
though they were either obese or overweight and this may be because the average age of study sample was around thirties. Two third of females participated in the study were with family history of obesity and most of the family history either from mother or father side. This is in agreement with previous research results in other countries. The risk of obesity is determined by not only specific genotypes but also gene-gene interactions. However, there are still challenges associated with detecting gene-gene interactions for obesity. ${ }^{20}$ Like many other medical conditions, obesity is the result of interplay between genetic and environmental factors. ${ }^{21}$

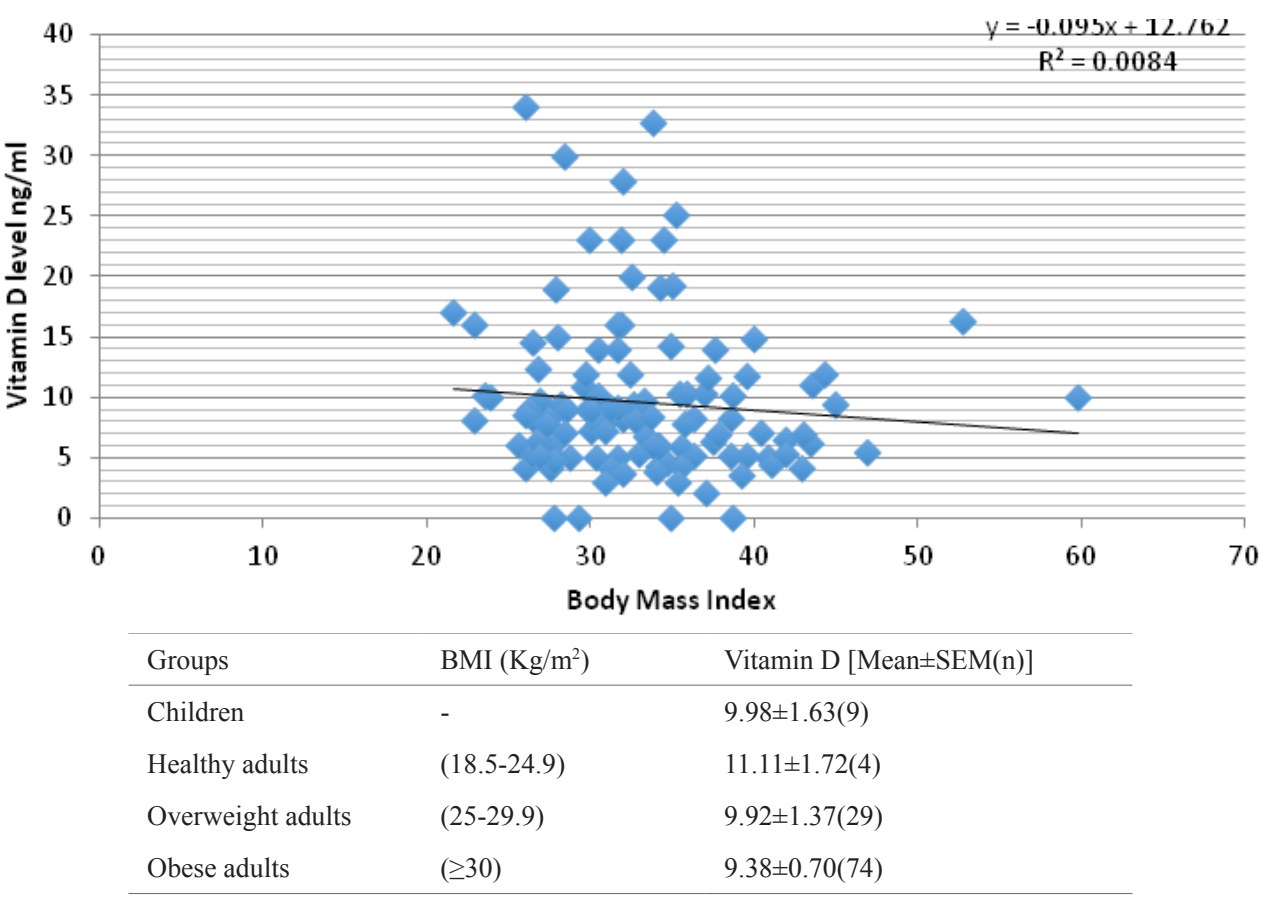

Figure 2 Vitamin D level among whole study population.

Study sample of Libyan females was classified into four groups (children, healthy adults, over weight adults and obese adults) based on age and BMI and according to the WHO criteria. The number of healthy individuals and children in this study was small compared to the other 2 groups and we could not hire healthy individuals from outside the clinics because it was difficult to convince them to offer samples for clinical investigation tests including measurement of vitamin D level, for research purposes, especially with the fact that vitamin D level measurement is costly. All study groups showed a severe deficiency in vitamin D. Even though, $28.33 \%$ of study sample were already on vitamin $\mathrm{D}$ therapy course but they were still suffering from a deficiency of vitamin $\mathrm{D}$, noting that most of other clinical investigation tests reported were within the normal range compared to reference values. Exact reason for vitamin D deficiency is not known. It may be due to environmental factors, inadequate exposure to sunlight, age that reduces the base material consisting of vitamin D in the skin, mal-absorption of vitamin $\mathrm{D}$ in the small intestine because of the presence of disease in the intestine, weight gain leading to collection of vitamin D in fat, as well as malnutrition, liver disease and kidney disease, patients taking epilepsy drugs or even some genetic diseases in children. It may be worth to state that before few decades, infantile rickets in Libya was attribute to low maternal and cord blood 25(OH)D levels. ${ }^{22}$

According to the WHO, in 2014, more than 1.9 billion adults, 18 years and older, were overweight. Of these over 600 million were obese. Taking into account the association between vitamin D deficiency and obesity, these two morbid events may constitute important current health issues during this period. Different theories can be proposed to explain the relationship between obesity and vitamin D deficiency.
First because of issues of low social acceptance, it is suggested that obese individuals reduce their exposure to sunlight, perform fewer outdoor activities and/or use clothes that cover more of the body, which limits exposure to the sun and, consequently, cutaneous vitamin D synthesis. However, in a study based on the Framingham cohort, which evaluated the association between obesity and vitamin $\mathrm{D}$, it was reported that after adjustments for practicing outdoor physical activities, this theory was insufficient to explain the relationship between obesity and vitamin D deficiency. ${ }^{23}$ Thus different level of sun exposure seems to be an unlikely explanation for the relationship between vitamin $\mathrm{D}$ deficiency and adiposity. This may apply as well for Islamic wear by majority of Libyan females. On the other hand, some experimental data have suggested that vitamin D deficiency can favor greater adiposity by promoting increased parathyroid hormone levels and greater inflow of calcium into adipocytes, thereby increasing lipogenesis. ${ }^{24}$ Accumulated evidence suggests that $1.25(\mathrm{OH}) \mathrm{D}$ inhibits adipogenesis through action modulated by vitamin $\mathrm{D}$ dependent receptors. Thus depletion of vitamin $\mathrm{D}$ can lead to excessive differentiation of pre-adipocytes to adipocytes. ${ }^{25}$ Results from current study emphasize the prevalence of vitamin D deficiency in obese and overweight females, however, the impact of several confounding factors, such as diet intake, physical activity, educational level, season of the year and presence of secondary hyperparathyroidism, should be recognized as to the decrease in vitamin D level.

\section{Conclusion}

Vitamin D deficiency is common among overweight and obese Libyan females living in the Eastern region of the country. This study 
should be extended to measure vitamin D level among different ages and sexes and in all main cities within the country.

\section{Acknowledgments}

None.

\section{Conflicts of interest}

Authors declare that they have no conflict of interest concerning this article.

\section{References}

1. Khan MY, Gupta P, Bihari B, et al. A Review on Obesity and its Management. Int J Sci Eng Res. 2012;3(11):1-9.

2. WHO. Obesity and Overweight; 2015.

3. Deslypere JP. Obesity and cancer. Metabolism. 1995;44(9 Suppl 3):2427.

4. Lewington S, MacMahon S, Aromaa A, et al. Body-mass index and cause-specific mortality in 900000 adults: collaborative analyses of 57 prospective studies. Lancet. 2009;373(9669):1083-1096.

5. Peeters A, Barendregt JJ, Willekens F, et al. Obesity in Adulthood and Its Consequences for Life Expectancy: a life-table analysis. Ann Intern Med. 2003;138(1):24-32.

6. Elmehdawi RR, Albarsha AM. Obesity in Libya: a review. Libyan $J$ Med. 2012;7:19086.

7. Benghazi diabetes and endocrine center: Statistics. Libya, Benghazi: Ministry of Health; 2009.

8. Dakhil FO, Zew M, Ahmad M, et al. Pattern of hypertension in Ibn Sina hypertension clinic, Benghazi-Libya. Garyounis Med J. 2002;19:5660.

9. Najem F, Elmehdawi R, Swalem A. Clinical and Biochemical Characteristics of Polycystic Ovary Syndrome in Benghazi- Libya; A Retrospective study. Libyan J Med. 2008;3(2):71-74.

10. National Survey of Non Communicable Disease Risk Factors. Libya: Tripoli Minister of Health; 2009.

11. Holick MF. Vitamin D Deficiency. N Engl J Med. 2007;357(3):266281.
12. Stroud ML, Stilgoe S, Stott VE, et al. Vitamin D - a review. Aust Fam Physician. 2008;37(12):1002-1005.

13. Heaney RP. Functional indices of vitamin $D$ status and ramifications of vitamin D deficiency. Am J Clin Nutr. 2004;80(6 Supl1):1706S-1709S.

14. McCullough M. Vitamin D deficiency in adults. Australian Prescriber. 2010;33:103-106.

15. Binkley N, Novotny R, Krueger D, et al. Low Vitamin D Status despite Abundant Sun Exposure. J Clin Endocrinol Metab. 2007;92(6):21302135 .

16. Adams JS, Hewison M. Update in vitamin D. J Clin Endocrinol Metab. 2010;95(2):471-478.

17. Correale J, Ysrraelit MC, Gaitán MI. Immunomodulatory effects of Vitamin D in multiple sclerosis. Brain. 2009;132(Pt 5):1146-1160.

18. Bener A, Al-Hamaq AO, Saleh NM. Association between vitamin d insufficiency and adverse pregnancy outcome: Global comparisons. Int $J$ Womens Health. 2013;5:523-531.

19. Mason C, Xiao L, Imayama I, et al. Vitamin D(3) supplementation during weight loss: a double-blind randomized controlled trial. Am J Clin Nutr. 2014;99(5):1015-1025.

20. Yang W, Kelly T, He J. Genetic epidemiology of obesity. Epidemiol Rev. 2007;29:49-61.

21. Albuquerque D, Stice E, Rodríguez-López R, et al. Current review of genetics of human obesity: from molecular mechanisms to an evolutionary perspective. Mol Genet Genomics. 2015;290(4):11911221.

22. Elzouki A, Legnain M, Markstead T. Vitamin D nutritional status of neonates and pregnant women in Benghazi. Garyounis Med J. 1983;6:735-737.

23. Cheng S, Massaro JM, Fox CS, et al. Adiposity, Cardiometabolic Risk, and Vitamin D Status: The Framingham Heart Study. Diabetes. 2010;59(1):242-248

24. Wood RJ. Vitamin D and adipogenesis: new molecular insights. Nutr Rev. 2008;66(1):40-46.

25. Martini LA, Wood RJ. Vitamin D status and the metabolic syndrome. Nutr Rev. 2006;64(11):479-486. 